American Journal of Animal and Veterinary Sciences 2 (2): 46-49, 2007

ISSN 1557-4555

(C) 2007 Science Publications

\title{
Effect of pH on the Conformation and Biological Activity of Clostridium septicum Alpha-toxin, a Pore-forming Hemolysin
}

\author{
${ }^{1}$ Hang'ombe, B.M., ${ }^{2}$ Kohda, T., ${ }^{2}$ Mukamoto, M. and ${ }^{2}$ Kozaki, S. \\ ${ }^{1}$ University of Zambia, School of Veterinary Medicine, Department of Paraclinical studies, P. O. Box \\ 32379, Lusaka, Zambia \\ ${ }^{2}$ Laboratory of Veterinary Epidemiology, Graduate School of Life and Environmental Sciences, Osaka \\ Prefecture University, 1-1 Gakuen-cho, Sakai, Osaka 599-8531, Japan
}

\begin{abstract}
The effects of $\mathrm{pH}$ on the pore-forming Clostridium septicum alpha-toxin that causes myonecrosis was assessed at $\mathrm{pH}$ 5.0, 7.0 and 9.0 by measuring circular dichroism and its biological activity. Incubation of the toxin at pH 5.0 increased the hemolytic activity measured in murine red blood cells. On the other hand, incubation of the toxin at $\mathrm{pH} 9.0$ drastically reduces the biological activity of the toxin by five-fold. This study presents the first evidence of the effect of $\mathrm{pH}$ on the functional properties of alpha-toxin directly related to the common disease caused by C. septicum in animals and humans i.e. traumatic and non traumatic gas gangrene.
\end{abstract}

Key words: Clostridium septicum; alpha-toxin, hemolytic activity; lethality; pH

\section{INTRODUCTION}

Alpha-toxin is a major exotoxin produced by strains of the Gram-positive bacterium Clostridium septicum. As a result of alpha-toxin, $C$. septicum has been implicated as a cause of exogenous (traumatic) and endogenous (non-traumatic) myonecrosis, which are rapidly fatal diseases in humans and animals ${ }^{[1,2]}$. The toxin is secreted as a water-soluble protoxin which requires proteolytic digestion for its activity. In vivo it is activated by furin, which is present on cell surfaces of eukaryotic cells ${ }^{[3]}$. The activation is necessary for subsequent induction of oligomerization and ultimate insertion of the oligometric complex into the plasma membrane of mammalian cells as activation exposes hydrophobic domains ${ }^{[4,5,6] \text {. }}$

The factors, which may influence the conformational changes of the toxin, on biological membranes are poorly understood as these membranes are negatively charged through their constituents consisting of the phospholipid, glycolipid and

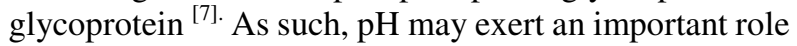
in the activity of $C$. septicum alpha-toxin. It is interesting then to determine if there is a simple relationship between conformation and biological activity. Taking into account these antecedents, the purpose of this work was to study the effect of $\mathrm{pH}$ on the stability of alpha-toxin and relate the effects to its biological activity.

\section{MATERIALS AND METHODS}

C. septicum alpha toxin was purified and activated as previously described ${ }^{[6,8]}$. The protein concentration was determined with a BIO-RAD protein assay kit (BIO-RAD laboratories, Hercules, CA) according to the manufacturer's instructions. Bovine plasma gamma globulin was used as the protein standard.

Following purification and activation, the toxin was subjected to a phosphate buffer under different $\mathrm{pH}$. Samples containing a final protein concentration of 10 $\mu \mathrm{g} / \mathrm{ml}$ were prepared and then dialyzed under the respective buffers overnight at $4{ }^{\circ} \mathrm{C}$. After overnight dialysis, the $\mathrm{pH}$ of the sample toxins was adjusted to $\mathrm{pH}$ 7 and the effect of $\mathrm{pH}$ on the hemolytic activity was evaluated using the hemolytic assay as described by Hang'ombe et al. ${ }^{[9]}$ using murine erythrocytes. Structural conformation changes of the alpha toxin treated at different $\mathrm{pH}$ was examined using circular dichroism spectra. The circular dichroism spectra of the activated toxin $(0.1 \mathrm{mg} / \mathrm{ml})$ treated at $\mathrm{pH} \mathrm{5,7}$ and 9 was recorded on a Jasco 720 spectropolarimeter using $1 \mathrm{~mm}$ pathlength quartz cuvettes by integration of the signal over a $60 \mathrm{~s}$ period. The temperature was maintained constant at $298 \mathrm{~K}$, and in all cases a correction was made by subtraction of the integrated signal measured from a buffer blank over the same time scale.

The effect of $\mathrm{pH}$ on the lethality of alpha-toxin was assessed by determining the $50 \%$ lethal dose $\left(\mathrm{LD}_{50},\right)$ on

Corresponding Author: Hang'ombe, B.M., University of Zambia, School of Veterinary Medicine, P. O. Box 32379, Lusaka, Zambia.Tel: +260-97326288 Fax: +260-1-293727 
six-weeks-old ddy mice (four per group). The mice were injected intravenously with $1 \mu \mathrm{g}, 0.5 \mu \mathrm{g}, 0.25 \mu \mathrm{g}$ and $0.125 \mu \mathrm{g}$ of activated alpha toxin, treated at $\mathrm{pH} 5,7$ and 9. After 72 hours, cumulative mortality data were used to estimate the $\mathrm{LD}_{50}$ values ${ }^{[10]}$.

\section{RESULTS}

The steady-state intrinsic fluorescence spectra of the $\mathrm{pH}$ treated toxins were recorded for $\mathrm{pH} \mathrm{5,7}$ and 9 (figure 1).

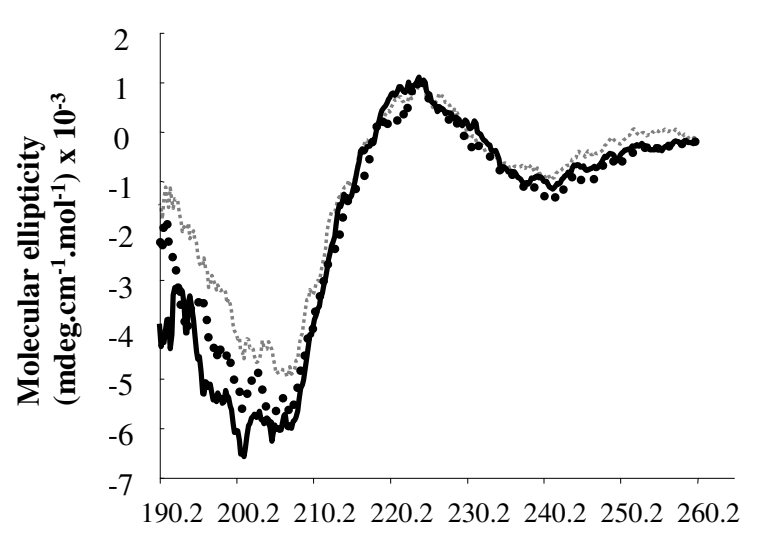

Wavelength (nm)

Fig. 1: Circular dichroism (CD) analysis of activated alpha-toxin $(0.1 \mathrm{mg} / \mathrm{ml})$ treated at different $\mathrm{pH}$. $\mathrm{pH} 5$ (square dots), $\mathrm{pH} 7$ (round dots) and $\mathrm{pH} 9$ (solid line).

A clear shift in molecular ellipticity was observed from $190 \mathrm{~nm}$ to $210 \mathrm{~nm}$ wavelength, indicating typical predominantly $\beta$-sheet protein in the native state. The molecular ellipticity decreased with high $\mathrm{pH}$ especially at around $200 \mathrm{~nm}$ wavelength. Further analysis of the CD spectra shows insignificant differences after $210 \mathrm{~nm}$. This observation was made even when the alpha-toxin was brought back to $\mathrm{pH} 7$ after incubation at $\mathrm{pH} 5$ and 9 .

In order to assess the effect of $\mathrm{pH}$ on alpha-toxin biological activity, the toxin incubated at $\mathrm{pH} \mathrm{5,7}$ and 9 was evaluated for its hemolytic activity in standard conditions ( $\mathrm{pH}$ 7.0). Preincubation of the toxin at $\mathrm{pH} 5$ and 9 produced changes in hemolytic activity (figure 2). On the other hand, a considerably reduced hemolytic activity was observed at $\mathrm{pH} 9$. The changes in the toxin elicited by incubation at $\mathrm{pH} 5$ and 9 are irreversible, since re-treatment at $\mathrm{pH} 7 \mathrm{did}$ not allow recovery to what is observed at $\mathrm{pH} 7$.

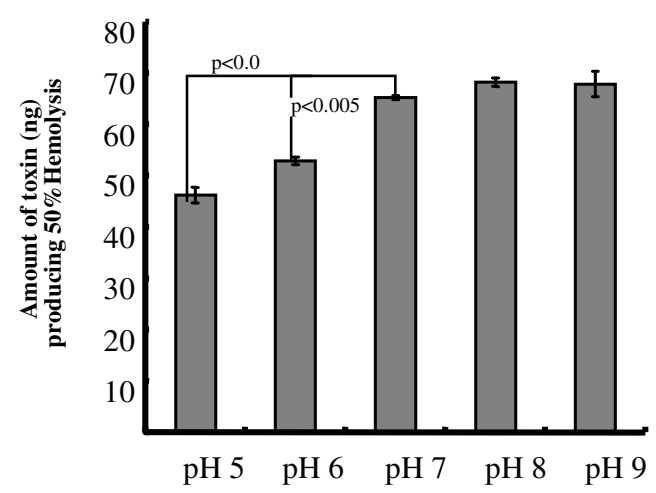

Fig. 2: Effect of $\mathrm{pH}$ on the activity of the activated alpha-toxin. The $\mathrm{pH}$ effect was investigated using a phosphate buffer of $\mathrm{pH} 5,6,7,8$ and 9. The $\mathrm{pH}$ of each test sample was adjusted to $\mathrm{pH}$ 7 before hemolytic assay. The data shows amount of toxin causing $50 \%$ hemolysis and represents means \pm SEM from multiple experiments.

The lethality of the toxin was also evaluated as indicated in table 1. As can be observed, at a lower $\mathrm{pH}$ of 5 there was an increase in lethality, while at $\mathrm{pH} 9$, a decrease in lethality was observed. The $\mathrm{LD}_{50}$ of $\mathrm{pH} 5$ and 7 was at least five-fold higher than that of $\mathrm{pH} 9$, revealing the effect of $\mathrm{pH}$ on the biological activity of the toxin.

Table 1: Lethal toxicity of Activated C. septicum alpha-toxin in mice treated at $\mathrm{pH} \mathrm{5,7}$ and 9 using the intravenous route

\begin{tabular}{cc}
\hline $\mathrm{pH}$ & Lethal Dose $_{50} / \mathrm{mg}$ of toxin \\
\hline 5 & $7.1 \times 10^{3}$ \\
7 & $6.7 \times 10^{3}$ \\
9 & $1.3 \times 10^{3}$ \\
\hline
\end{tabular}

\section{DISCUSSION}

Membrane damaging activity by alpha-toxin is a consequence of the formation of a transmembrane pore, a process that has been extensively studied in vitro through the investigation of the interaction of the protein with artificial membranes ${ }^{[5,11]}$. In this study we have evaluated the effect of $\mathrm{pH}$ on the structural and biological stability of the native toxin. It has been demonstrated that $\mathrm{pH}$ has an effect on the biological activity of alpha-toxin and produces significant changes in the protein secondary conformation that is 
irreversible. This observation has been made with other pore-forming toxins such as staphylococcal toxin, Bacillus anthracis protective antigen and the cytolysin from the sea anemone ${ }^{[12,13]}$. These toxins have been demonstrated to adopt a partially unfolded and more flexible conformation in solution at $\mathrm{pH} \square$ 4.5. It has been suggested therefore that upon association of these toxins with biological membranes, the reduced local $\mathrm{pH}$ triggers the formation of a partially unfolded state, which is functionally associated with the pore-forming process of penetration ${ }^{[14]}$. Therefore the $\mathrm{pH}$ induced conformation changes in the toxin can affect its capacity to form pores once adsorbed at the interface as observed by other workers $[15,16]$. The decrease in hemolytic activity of the toxin pre-exposed to $\mathrm{pH} 9$ can also be due to a weaker toxin-to-toxin monomer interaction or the lack of capacity of the modified toxin to penetrate and organize inside the membrane.

The alpha-toxin of $C$. septicum has now been confirmed as essential for virulence ${ }^{[17]}$ since, virulence testing of isogenic series of $C$. septicum strains consisting of the wild type and mutants revealed that the development of fulminant myonecrosis in mice was dependent on the ability to produce a functional hemolytic alpha-toxin. It should also be noted that anaerobic conditions required for optimal growth of $C$. septicum produce an acid $\mathrm{pH}$, which in turn may enhance the activity of alpha-toxin. Pathogenesis of malignant edema in animals involves the subsequent creation of an anaerobic niche with a sufficient low redox potential and an acid $\mathrm{pH}{ }^{[18]}$. Although these findings are consistent with the results of the present study, it remains to be ascertained how the pathology of myonecrosis would progress at different $\mathrm{pH}$. In conclusion, our study provides the results of the first indication that the low $\mathrm{pH}$ in an anaerobic environment might favor the degree of alpha-toxin lethality.

\section{ACKNOWLEDGMENTS}

This work was supported in part by Grants-in-Aid for Scientific Research from Japan Society for the Promotion of Science.

\section{REFERENCES}

1. Johnson, S., M. R. Driks, R. K. Tweten, J. Ballard, D. L. Stevens, D. J. Anderson and E. N. Janoff, 1994. Clinical courses of seven survivors of Clostridium septicum infection and their immunologic responses to alpha toxin. Clin. Infect. Dis., 19:761 - 764.
2. Willoughby, D. H., A. A. Bickford, G. L. Cooper and B. R Charlton, 1996. Periodic recurrence of gangrenous dermatitis associated with Clostridium septicum in a broiler chicken operation. J. Vet. Diagn. Invest., 8:259-261.

3. Gordon, V. M., R. Benz, K. Fujii, S. H. Leppla and R. K. Tweten, 1997. Clostridium septicum alpha-toxin is proteolytically activated by furin. Infect. Immun., 65:4130-4134.

4. Shin, D. J., J. J. Lee, H. E. Choy and Y. Hong, 2004. Generation and characterization of Clostridium septicum alpha toxin mutants and their use in diagnosing paroxysmal nocturnal hemoglobinuria. Biochem. Biophys. Res. Commun., 324:753-760.

5. Ballard, J., Y. Sokolov, W. L. Yuan, B. L. Kagan and R. K. Tweten, 1993. Activation and mechanism of Clostridium septicum alpha-toxin. Mol. Microbiol., 10:627-634.

6. Ballard, J., A. Bryant, D. Stevens and R. K. Tweten, 1992. Purification and characterization of the lethal toxin (alpha-toxin) of Clostridium septicum. Infect. Immun., 60:784-790.

7. Tran, L. B., V. Vachon, L. J. Schwartz and R. Laprade, 2001. Differential effects of $\mathrm{pH}$ on the pore-forming properties of Bacillus thuringiensis insecticidal crystal toxins. Applied and Environmental Microbiology., 67:4488-4494.

8. Hang'ombe, B. M., T. Kohda, M. Mukamoto and S. Kozaki, 2005. Relationship between Clostridium septicum alpha-toxin activity and binding to erythrocyte membranes. J. Vet. Med. Sci., 67: 69 74.

9. Hang'ombe, B. M., T. Kohda, M. Mukamoto and S. Kozaki, 2006. Purification and sensitivity of Clostridium chauvoei hemolysin to various erythrocytes. Comp. Immun, Microbiology \& Infectious Diseases., 29: 263 - 268.

10. Reed, L. J and H. Muench, 1938. A simple method of estimating fifty per cent endpoints. American Journal of hygiene., 27: 493-497.

11. Melton, J. A., M. W. Parker, J. Rossjohn, J. T. Buckley and R. K. Tweten. 2004. The identification and structure of the membrane-spanning domain of the Clostridium septicum alpha toxin. J. Biol. Chem., 279:14315-14322.

12. Alvarez, C., F. I. Pazos, E. M. Lanio, D. Martinez, S. Schreier, F. Casallanovo, M. A. Campos and E. Lissi, 2001. Effect of $\mathrm{pH}$ on the conformation, interaction with membranes and hemolytic activity of sticholysin II, a pore forming cytolysin from the sea anemone Stichodactyla helianthus. Toxicon., 39: 539-553. 
13. Bortoleto, K. R and J. R. Ward, 1999. A stability transition at mildly acidic $\mathrm{pH}$ in the alpha-hemolysin (alpha-toxin) from Staphylococcus aureus. FEBS Letters., 459:438-442.

14. Van der Goot, F. G., J. N. Gonzalez, J. H. Lakey and F. Pattus, 1991. A "molten globule" membrane-insertion intermediate of pore-forming domain of colicin A. Nature., 354:408-410.

15. Zakharov, S. D., J. B. Heymann, Y. L. Shang and W. A. Cramer, 1996. Membrane binding of the colicin E1 channel: activity requires an electrostatic interaction of intermediate magnitude. Biophys. J., 70:2774-2783.
16. Nordera, P., M. Serra Dalla and G. Menestrina, 1997. The adsorption of Pseudomonas aeruginosa exotoxin A to phospholipid monolayers is controlled by $\mathrm{pH}$ and surface potential. Biophys. J., 73:1468-1478.

17. Kennedy, C. L., E. O. Krejany, L. F. Young, J. R. O'Connor, M. M. Awad, R. L. Boyd, J. J. Emmins, D. Lyras and J. I. Rood, 2005. The alpha-toxin of Clostridium septicum is essential for virulence. Mol. Microbiol., 57:1357-1366.

18. Stevens, D. L and A. E. Bryant, 2002. The role of Clostridial toxins in the pathogenesis of gas gangrene. Clin. Infect. Dis., 35:S93-S100. 